\title{
Competency based medical education: Initiatives beyond the classroom
}

\author{
Vedprakash Mishra
}

Chancellor, Krishna Institute of Medical Sciences (Deemed to be University), Karad, Maharashtra, India

Corresponding Author:

Email: drvedprakashmishra@gmail.com

Education in terms of process has not only to be beyond boundaries but also cannot be placed in any cage of any type. It is only when it is free from any limitations of any type it manifests into fulfillment of its objectives in desired and optimal manner.

Precisely it must be in this context that Swami Vivekanand defined education as a process which results in manifestation of perfection already present within man and simultaneously defined religion as 'manifestation of divinity already present in man'. If the two definitions are put together then it categorically brings out that the need is manifestation of 'divine perfection' already present in man.

It is in this backdrop that one is required to appreciate the scope, role and relevance of education beyond the contours and limitations of four walls of the classical classrooms. No doubt bulk of formal education over a period of time that has been put into operation and practice has been and continues to be 'classroom based' but then the concept of education beyond classroom has its own sway and has gone to prove its relevance and impact beyond all considerations of 'ifs' and 'buts' of any and all types.

The material consideration is the myth that is held by all concerned is that 'competency based education' in terms of its imparting and manifestation has to be 'classroom based' for various reasons and considerations which have been advocated in several ways by different leading authorities.

It has also been held as a strong belief that competency based education being an outcome based education needs to be dispensed with diligent care and caution with periodic performance appraisal at spaced timings in such a way that the operational continuum is dispensed resulting in desired outcome. The task dispensation that is at hand is structuring ability to be transformed into a formulated skill and its ultimate strengthening resulting in manifestation of a competency.

To say that this conversion would not be feasible outside the domain of structured dispensation perhaps is more of a myth than reality. As a matter of fact there are $n$ number of influences which shape a learner which are outside the precincts not only of a classroom but even beyond the domain of formal structuring of any type. Contemporary peer learning by a learner coconsciously turns out to be the most subtle way of learning with a very significant degree of impact. Being conscious of the fact that one is learning as a learner is more inhibitive than when the learner is not even conscious that the process of learning is on and his gains out of the same are open ended.

As such, it is evident that learning beyond classrooms is an established phenomena and it takes place round the clock consciously subconsciously and for that matter even unconsciously at wide and varied time. The real purport is to decipher its mechanisms and put them into educational principles for the purposes of better convertibility and desired attainment.

It is this aspect which needs a bit of greater understanding for a decisive indulgence under the rubric of an appropriate scientifically structured mechanism which would pave the way for the same in a significantly focused, purposive and meaningful manner. It is this arena which if tapped scientifically with focused clarity and decisive purpose is bound to open a plethora of vistas hitherto unknown and untapped.

Let us venture into this treasure land which is bound to resultant manifestation of many new and novel dimensions in the domain of competency based learning beyond the four walls of classrooms in terms of it being structured yet liberal and lose, open ended yet demarcated and free flowing yet objectively measurable. The arenas that have remained virgin on the said count need joint and several indulgences which are bound to unfold and evolve answers to several myths which are held high as definitive in character by many leading and knowledgeable educationists. Let us tap the same with sense of pragmatic determination to decisively evolve a desired paradigm shift which is bound to create wider dimensions of scope of competency based education beyond class rooms. 